\title{
Сучасні підходи до лікування гострої емпіеми плеври (огляд літератури)
}

\begin{abstract}
Гостра емпієма плеври (ГЕП) є одним із найскладніших захворювань, з яким щорічно стикаються не тільки торакальні хірурги, а й терапевти та лікарі загальної практики. Незважаючи на успіхи сучасної фармакології та стрімкий розвиток хірургічних методик, результати лікування ГЕП часто незадовільні. Це пов'язано й з неправильним лікуванням та пізньою діагностикою ускладнень пневмонії. Стандартом хірургічного лікування ГЕП багато років вважали дренування плевральної порожнини. Але у ситуаціях, коли у хворого наявна багатоосумкована ГЕП, доводилося дренувати кожне осумкування окремо, що створює додаткові труднощі як для хірурга, так і для хворого. В останні роки широкого розповсюдження у світі набули різні види відеоторакоскопічних операцій (ВТО), у тому числі й при лікуванні ГЕП. Однак тривають дискусії щодо правильної тактики використання ВТО при ГЕП. Також залишаються актуальними питання боротьби з ускладненнями ГЕП, в лікуванні яких немає єдиної думки фахівців. Отже, метою нашої роботи був аналіз сучасної вітчизняної та зарубіжної літератури щодо тактики лікування хворих на ГЕП із використанням сучасних відеоторакоскопічних малоінвазивних технологій.

ВТО дозволяють успішно поєднувати можливості закритих та відкритих операційних втручань у торакальній хірургії. Безумовною перевагою ВТО також є зменшення крововтрати та часу, необхідного на виконання власне втручання. Якщо неможливо виконати повністю закриту ВТО, доцільно доповнити її міні-торакотомією. Аналіз досвіду застосування такої методики свідчить про значно ширші можливості інтраплевральних маніпуляцій. Виконання ВТО при ГЕП дозволяє досягти скорочення терміну стаціонарного лікування та знизити процент випадків хронізації процесу. Тяжкі ускладнення ГЕП, наприклад, залишкові порожнини та плевро-легеневі нориці, потребують індивідуального підходу до кожного хворого. Сучасним і перспективним методом боротьби із залишковими порожнинами при ГЕП є вакуум-терапія.
\end{abstract}

Ключові слова: відеоторакоскопічні операції; емпієма плеври; плевро-легеневі нориці; залишкова порожнина.

Емпієма плеври є складним розділом сучасної торакальної хірургії, навколо тактики лікування якої полеміка не припиняється не зважаючи на успіхи та досягнення малоінвазивних методів. Сьогодні, за даними вітчизняних і зарубіжних дослідників, не спостерігається скорочення частоти гострих гнійно-деструктивних захворювань легень, що ускладнюються гостою емпіємою плеври (ГЕП) та сягає від 19,1 - 73,0 \% [1-3]. При цьому летальність становить 5 - 25 \% [2, 4-8].

Мета роботи: проаналізувати можливості використання різних відеоторакоскопічних методів лікування ГЕП.

Несвоєчасна діагностика ГЕП часто призводить до тривалого та неефективного лікування хворих у непрофільних терапевтичних стаціонарах, що закінчується розвитком тяжких ускладнень.

Основним методом лікування при ГЕП залишається дренування 3 постійною аспірацією та промиванням порожнини емпієми [3, 9]. Але деякі автори вважають, що на ранніх стадіях ГЕП можливо вилікувати плевральними пункціями, особливо в перші 4-5 днів від початку захворювання, після чого необхідно переходити до дренування плевральної порожнини [9].

Walker C.А. та співавт. довели, що такі біохімічні показники плевральної рідини, як вміст глюкози менше 40 мг/дл або $\mathrm{pH}$ менше 7,1 свідчать про необхідність дренування плевральної порожнини [10]. Porcel J.M. та співавт. вважають, що показаннями до дренування плевральної порожнини $\epsilon$ не тільки рівень глюкози або $\mathrm{pH}$ плевральної рідини, а й якщо рідина займає половину плевральної порожнини або більше, гнійний ексудат при пункції, або ріст культури при бактеріальному дослідженні [11].

Але якщо дренування не дає бажаного результату, то потрібно переходити до більш інвазивних методів лікування. 3 огляду на власний досвід, ми вважаємо, що раннє виконання відеоторакоскопічних операцій (ВТО) знижує кількість післяопераційних ускладнень, термін дренування плевральної порожнини, термін лікування хворого у стаціонарі та процент переходу гострого процесу в хронічний, що підтверджується даними інших авторів [12-14]. Так, наприклад, О. О. Ясногодський та співавт. провели аналіз результатів лікування хворих на неспецифічну емпієму плеври з 1977 до 2015 р., загальна летальність знизилась $з$ 4,9 до 3,2 \%, тоді як післяопераційна летальність знизилася з 19,5 \% до нуля за рахунок впровадження ВТО [14].

Під час ВТО можливо ефективно санувати плевральну порожнину у 77-85 \% хворих, а також набрати матеріал на гістологічне дослідження для встановлення точної етіології захворювання [14, 
15]. Частота розвитку післяопераційних ускладнень при даному виді операцій становить 4-14 \%, а необхідність конверсії в торакотомію виникає у 3,1-41,6 \% пацієнтів [15, 16].

Але не у всіх хворих при ГЕП можливо домогтися адекватної санації плевральної порожнини після першої ВТО. Так, В. І. Нікольський та співавт. запропонували виконувати програмовані динамічні торакоскопії з інтервалами у 5-7 діб. При виконанні повторної ВТО оцінювали стан вісцеральної та парієтальної плеври, здійснювали її біопсію для морфологічного моніторингу динаміки запального процесу, виявляли ранню стадію формування внутрішньоплевральних ускладнень, усували дислокацію дренажів. У досліджуваній групі хворих вдалося знизити летальність з 4,1 до $0,7 \%[4]$.

Якщо неможливо виконати повністю закриту ВТО, то нерідко використовується варіант відеоасистованої торакоскопії (ВАТС). При цьому виді втручання камера заводиться до плевральної порожнини також через торакопорт, але для зручності виконання декортикації операцію доповнюють мініторакотомним доступом. Так, Potaris K. та співавт. порівнювали результати лікування 122 хворих з ГЕП, частина цих хворих була прооперована відеоасистовано. У своєму дослідженні автори роблять висновок, що відеоасистовані операції показують добрий результат у хворих з I-II типом ГЕП, тоді як при III типі краще виконувати відкриту торакотомію, хоча вона й пов'язана $з$ досить високим ризиком смерті та ускладнень [17]. У інших дослідженнях було продемонстровано, що ВАТС ефективна при лікуванні постпневмонектомічної емпієми плеври, при умові відсутності великої плевро-легеневої нориці або за наявності мікронориці [18].

У свою чергу, Є. П. Ізмайлов та співавт. вважають, що при лікуванні ГЕП найбільш виправданою є відеоасистована бокова мініторакотомія, виконана в період від 1-1,5 місяця після початку розвитку емпієми плеври. Застосування подібної тактики дозволило у 185 (91,1 \%) хворих домогтися клінічного одужання і ліквідувати залишкову порожнину [19].

Ясногородський О. О. також використовує мінідоступ і вважає перевагою такого варіанту можливість подвійного огляду оперованої зони, достатнє освітлення та можливість використання як традиційних, так і ендоскопічних інструментів. 3 82 хворих з емпіємою плеври тільки у 10 виникла необхідність розширити мінідоступ до стандартної торакотомії, і у більшості пацієнтів вдалося адекватно санувати емпіємну порожнину [14].
Нині набирає популярності варіант ВТО при ГЕП, коли усі хірургічні маніпуляції у плевральній порожнині виконують через один мінідоступ без встановлення додаткових торакопортів. Bongiolatti S. та співавт. порівняли результати лікування хворих із гострою емпіємою плеври, яких оперували за методикою монопортової відеоторакоскопії із хворими, яким необхідне виконання торакотомії. При виконанні монопортової ВТО авторам вдалося домогтися меншої крововтрати $(118 \pm 80$ мл проти $247 \pm 140$ мл), зменшення тривалості дренування плевральної порожнини (5,6 \pm $1,4$ проти $10,6 \pm 4,4)$, зменшення терміну госпіталізації (6, $7 \pm 1,9$ проти $12,2 \pm 4,7$ дня) та зниження кількості ускладнень (10 \% проти 16 \%), з чого можна зробити висновок, що даний метод є безпечним та ефективним варіантом лікування ГЕП, що потребує подальшого вивчення [20].

У хворих з ГЕП, що ускладнена плевро-легеневою норицею, значно знижується рухливість легеневої тканини, що призводить до неефективного відтоку емпіємної рідини по плевральному дренажу. Це призводить до появи таких ускладнень, як залишкові порожнини та підвищує процент хронізації захворювання.

Автори у своїх публікаціях пропонують різні способи санації плевральної порожнини та різні методи усунення негерметичності легеневої тканини, наприклад, за допомогою ендобронхіальних оклюзій, застосування медичних клеїв, лазерної коагуляції або резекції легені [3, 12, 21]. Однак усі ці методи мають низьку ефективність через те, що оперативне втручання проводиться при гнійно-некротичному процесі, що призводить до прорізування запаленої легеневої тканини та сприяє неспроможності “заварених” тканин. Автори пропонують поєднувати різні методи лікування з тимчасовою обтурацією бронхів, оскільки вони доповнюють одне одного та у комплексі мінімізують свої недоліки [12, 22].

Що стосується коагуляції норицевого ходу, то автори здебільшого вважають, що у такий спосіб можливо позбутися лише нориць невеликого діаметра або його потрібно поєднувати з іншими варіантами лікування нориць, наприклад, міопластикою [23].

Цеймах Є. О. та співавт. пропонують метод тимчасової ендобронхіальної оклюзії за допомогою фібробронхоскопа, який сприяє одужанню у 91,7 \%, тоді як традиційна ендобронхіальна оклюзія поролоновим обтуратором була ефективна тільки у 69 \% хворих із пострезекційними плевро-легеневими норицями. Середній термін перебування хворих у стаціонарі з встановленим 
клапанним бронхоблокатором склав $(69,5 \pm 2,1)$ доби [24].

Хрупкін В. І. та співавт. в своєму дослідженні використовували метод тимчасової ендобронхіальної оклюзії клапанними бронхоблокаторами або поролоновими обтураторами при ГЕП зі стійкими плевро-легеневими норицями з метою ліквідації залишкової плевральної порожнини та створення умов для загоєння нориць. Тимчасову оклюзію бронхів виконували в найближчу добу після ВТО із санацією, що в цілому дозволило домогтися скорочення терміну госпіталізації в середньому на 9 ліжко-днів [12].

Для лікування бронхіальних нориць у хворих емпіємою плеври після пульмонектомії автори часто використовують відкритий доступ до неспроможної бронхіальної кукси з ушиванням її дефекту або резекцією кукси. Такі операції поєднуються з видаленням капсули емпієми та торакоміопластикою для усунення залишкової порожнини [24, 25].

При наявності ГЕП із стійкою залишковою порожниною деякі автори пропонують місцево використовувати вакуумні пов'язки - так званий метод вакуумно-асистованої терапії (VAC® терапія).

Haghshenasskashani А. та співавт. провели ретроспективний аналіз лікування хворих з ГЕП, котрим до залишкової порожнини встановлювали поліуретанову губку та застосовували негативний тиск від -25 до -75 мм рт. ст. 3 плином часу тиск регулювався та змінювався до -125 мм рт. ст., а пов’язки змінювали кожні 2-5 днів. Дослідження показало значно більш коротку тривалість торакостомії у пацієнтів із застосуванням вакуум-терапії (ВТ) (39 \pm 17 днів) порівняно з пацієнтами, при лікуванні яких ВТ не застосовувалася (933 \pm 1422 днів) [26].

Groetzner та співавт. виявили безпечність використання ВТ у пацієнтів з бронхоплевральними норицями після покриття кукси бронха внутрішньогрудним м'язовим клаптем [27].

Барського Б. Г. та співавт. вивчали можливості та ефективність ВТ залишкових плевральних порожнин при ГЕП (41 пацієнт) та тривало перебігаючих плевритах, ускладнених ригідною легенею (68 пацієнтів).

Автори формували мініторакостому завдовжки 3-5 см, при необхідності з резекцією одного ребра, у проекції нижніх відділів залишкової порожнини, через яку здійснювали торакоскопічну санацію. Потім порожнину пухко заповнювали антимікробною марлею та тампонували губкою. Залежно від розмірів і форми порожнини залишкову порожнину встановлювали один або два дренажі та підключали до апарата вакуумної аспірації з розрідженням 80 мм рт. ст. Повторні перев’язки з торакоскопічною ревізією та санацією виконувалися на 3-5 добу. Як правило, після 2 перев'язок залишкова порожнина очищалась, тому переходили до активної аспірації в змінному режимі 20-60 мм рт. ст. з метою стимуляції кровопостачання та розвитку грануляційної тканини. Після очищення та зменшення залишкової порожнини сформовану торакостому закривали місцевими тканинами.

Автори наголошують, що у всіх пацієнтів обсяг залишкової порожнини стрімко зменшувався і незважаючи на наявність гною та фібрину при перших операціях, починаючи з першої перев'язки, жодного випадку збільшення кількості фібринозних накладень не спостерігали. Вони пов'язують це зі щільним приляганням антимікробних серветок до стінок порожнини за рахунок вакууму та з адекватною евакуацією ексудату з усієї поверхні порожнини емпієми. Також за допомогою ВТ забезпечували повну герметичність післяопераційної рани та всієї дренажної системи.

У результаті дослідження летальність сягала 3,6 \%, середня кількість перев'язок склала 4-5 на кожного пацієнта, а середній ліжко-день - 25 (від 12 до 42) ліжко-днів. То ж автори наполягають на подальшому вивченні та удосконаленні цього методу як альтернативи травматичній торакотомiї [28].

Perentes J. Y. та співавт. використовували ВТ у 21 хворого з інфікованими залишковими порожнинами після пневмонектомії. Госпітальна летальність склала 23 \%. Середня тривалість ВТ склала 23 дні (діапазон від 4 до 61 дня), а середнє число змін вакуум-пов'язок на одного пацієнта було 6 (від 2 до 14). Успішного закриття залишкових порожнин вдалось домогтися у 16 хворих [29].

Висновки. 1. ВТО операції дозволяють успішно поєднувати можливості як закритих, так і відкритих оперативних втручань у хірургії легень і плеври.

2. Виконання ВТО при ГЕП дозволяє покращити результати лікування хворих, скоротити термін стаціонарного лікування та знизити процент випадків хронізації процесу.

3. Такі ускладнення ГЕП, як залишкові порожнини та плевро-легеневі нориці, потребують індивідуального підходу до кожного хворого із ретельним підбором тактики їх закриття.

4. ВТО у поєднанні з ВТ є новим перспективним методом лікування ускладнених форм ГЕП. 


\section{СПИСОК ЛІТЕРАТУРИ}

1. Амарантов Д. Г. Клинико-анатомические характеристики острых неспецифических эмпием плевры у населения г. Перми / Д. Г. Амарантов, Р. Р. Барашкова, Е. А. Трофимова // Молодой ученый. - 2016. - № 1. - С. 72-74.

2. Применение торакоскопии в местном лечении неспецифической эмпиемы плевры / А. А. Дударев, А. М. Сухоруков, В. А. Большаков [и др.] // Bulletin of the International Scientific Surgical Association. - 2010. - Vol. 5, № 1. - P. 11-12.

3. EACTS expert consensus statement for surgical management of pleural empyema / M. Scarci, U. Abah, P. Solli [et al.] // Eur. J. Cardiothorac. Surg. 2015. - Vol. 48 (5). - P. 642-653.

4. Динамическая торакоскопия с применением торакопорта в лечении больных с неспецифической эмпиемой плевры / В. И. Никольский, С. Н. Логинов, М. С. Баженов, О. А. Семисаженов // Известия высших учебных заведений. Поволжский регион. - 2010. - № 4 (16). - С. 99-107.

5. Дужий I. Д. Питання епідеміології емпієми плеври / I. Д. Дужий, І. Я. Гресько, Ю. О. Міщенко // Український пульмонологічний журнал. - 2016. - № 3, додаток. - С. 60-62. 6. Макаров В. В. Современные аспекты санации плевральной полости у больных с острой эмпиемой плевры / В. В. Макаров // Буковинський медичний вісник. - 2008. - Т. 12, № 3. - С. 39-41.

7. Эндоскопическая торакальная хирургия : Руководство для врачей / А. М. Шулутко, А. А. Овчинников, О. О. Ясногородский, И. Я. Мотус. - М. : Медицина, 2006. - 392 с.

8. Thoracic empyema: current opinions in medical and surgical management / S. F. Lee, D. Lawrence, H. Booth [et al.] // Curr. Opin. Pulm. Med. - 2010. - Vol. 16, № 3. - P. 194-200.

9. Эмпиемы плевры. Частота возникновения, пункционная терапия, закрытое дренирование плевральной полости. Часть I / Е. А. Цеймах, А. В. Левин, П. Е. Зимонин, А. М. Самуйленков // Туберкулез и болезни легких. - 2009. - № 8. - C. 3-9.

10. Intrapleural alteplase in a patient with complicated pleural effusion / C. A.Walker, M. B. Shirk, M. M. Tschampel, J. A. Visconti. // Ann. Pharmacother. - 2003. - No. 37 (3). P. 376-379.

11. Porcel J. M. Parapneumonic pleural effusions and empyema in adults:current practice / J. M. Porcel, R. W. Light // Rev. Clin. Esp. - 2009. - Vol. 209, No. 10. - Р. 485-494.

12. Торакоскопические методы в комплексном лечении неспецифической эмпиемы плевры и гнойно-деструктивных заболеваний легких / В. И. Хрупкин, В. К. Гостищев, Д. В. Золотарев, Е. В. Дегтярева // Хирургия. - 2014. - № 10. - С. 1520.

13. Комбинированное хирургическое лечение эмпиемы плевры с применением видеоторакоскопии / В. Ю. Матвеев, Р. М. Хасанов, Р. Ф. Гайфуллин [и др.] // Актуальные проблемы медицины. - 2012. - Т. 2, № 8 (64). - С. 111-116. 14. Эволюция методов комплексного лечения больных с неспецифической эмпиемой плевры / О. О. Ясногородский, А. М. Шулутко, Т. П. Пинчук [и др.] // Хирургия. - 2017. № 4. - С. 24-29.

15. Можливості відеоторакоскопічної резекції легені в торакальній хірургії / П. П. Шипулін, В. В. Байдан, В. А. Мартинюк [та ін.] // Клінічна хірургія. - 2009. - № 9. - С. 43 - 46.
16. Video-assisted thoracoscopic surgery in the treatment of complicated parapneumonic effusions or empyemas: outcome of 234 patients / S. P. Luh, M. C. Chou, L. S. Wang [et al.] // Chest. - 2005. - No. 127. - P. 1427-1432.

17. Video-thoracoscopic and open surgical management of thoracic empyema / K. Potaris, P. Mihos, I. Gakidis, C. Chatziantoniou // Surg. Infect. (Larchmt). - 2007. - Vol. 8, No. 5. - P. 511-517.

18. Treatment of postpneumonectomy empyema with debridement followed by continuous antibiotic irrigation / T. Ng, B. A. Ryder, D. E. Maziak, F. M. Shamji // J. Am. Coll. Surg. 2008. - No. 206. - P. 1178-1183.

19. Результаты применения видеоассистированной миниторакотомии при лечении острой эмпиемы плевры / Е. П. Измайлов, С. Д. Родин, Т. А. Наумова [и др.] // 21-й Нац. конгр. по болезням органов дыхания : тезисы. - Уфа, 2011. - С. 101102.

20. Uniportal thoracoscopic decortication for pleural empyema and the role of ultrasonographic preoperative staging / S. Bongiolatti, L. Voltolini, S. Borgianni [et al.] // Interact. Cardiovasc. Thorac. Surg. - 2017. - Vol. 24, No. 4. - P. 560-566. 21. Колбашова Ю. Н. Применение мини-инвазивных методик в лечении эмпиемы плевры, осложненной бронхоплевральным свищом / Ю. Н. Колбашова, Р. М. Евтихов // Вестник Ивановской медицинской академии. - 2012. Т. 17, № 2. - С. 75-76.

22. Торакоскопическая хирургия / Е. И. Сигал, К. Г. Жестков, М. В. Бурмистров, О. В. Пикин. - М. : Дом книги, 2012. $-352 \mathrm{c}$.

23. Этапное лечение постпневмонэктомической эмпиемы / А. А. Шевченко, А. В. Кошевой, Е. А. Кашкаров [и др.] // Дальневосточный медицинский журнал. - 2015. - № 4. С. 108-110.

24. Применение клапанной бронхоблокации и видеоторакоскопии в комплексном лечении пиопневмоторакса / Е. А. Цеймах, А. В. Левин, И. В. Швецов, И. А. Бродер // Эндоскопическая хирургия. - 2011. - № 2. - С. 14-17.

25. Тактические вопросы лечения эмпиемы плевры, осложненной бронхоплевральными свищами / И. Ф. Слободенюк, А. А. Полежаев, К. Х. Нехай [и др.] // Тихоокеанский медицинский журнал. - 2011. - № 1. - С. 41-44.

26. Intrathoracic application of a vacuum-assisted closure device in managing pleural space infection after lung resection: is it an option? / A. Haghshenasskashani, M. Rahnavardi, T. D. Yan, B. C. McCaughan // Interact. CardioVasc. Thorac. Surg. - 2011. - No. 13. - P. 168-174.

27. Intrathoracic application of vacuum wound therapy following thoracic surgery / J. Groetzner, M. Holzer, D. Stockhausen [et al.]. // Thorac. Cardiovasc. Surg.. - 2009. - No. 57. - P. 417-420. 28. Однопортовые торакоскопические программированные санации и миниторакостомия с вакуум-терапией в лечении эмпиемы плевры / Б. Г. Барский, К. Г. Жесков, В. М. Козаченко [и др.]. // Высокотех. мед. - 2015. - № 3. - С. 30-39.

29. Vacuum-assisted closure device for the management of infected postpneumonectomy chest cavities / J. Y. Perentes, E. bdelnour-Berchtold, J. Blatter [et. al.] // J. Thorac. Cardiovasc. Surg. - 2015. - Vol. 149, No. 3. - P. 745-750. 


\section{REFERENCES}

1. Amarantov, D.G., Barashkova, R.R., \& Trofimova E.A. (2016). Kliniko-anatomicheskie kharakteristiki ostrykh nespetsificheskikh empiem plevry u naseleniya g. Permi [Clinicoanatomical characteristics of acute non-specific pleural empyema in the population of Perm]. Molodoy uchenyy - Young Scientist, 1, $72-74$ [in Russian].

2. Dudarev, A.A., Sukhorukov, A.M., Bolshakov, V.A., Fokin, V.A., \& Dudarev, V.A. (2010). Primenenie torakoskopii $\mathrm{v}$ mestnom lechenii nespetsificheskoy empiemy plevry [The use of thoracoscopy in the local treatment of nonspecific pleural empyema]. Bulletin of the International Scientific Surgical Association, 5 (1), 11-12. [In Russian].

3. Scarci M., Abah U., Solli P., Page A., Waller D., van Schil P., ... Cardillo G. (2015). EACTS expert consensus statement for surgical management of pleural empyema. Eur. J. Cardiothorac. Surg., 48 (5), 642-653. doi: 10.1093/ejcts/ezv272. Available from: https://academic.oup.com/ejcts/article/48/5/642/2465047/ EACTS-expert-consensus-statement-for-surgical

4. Nikolskiy, V.I., Loginov, S.N., Bazhenov, M.S., \& Semisazhenov, O.A. (2010). Dinamicheskaya torakoskopiya s primeneniem torakoporta $\mathrm{v}$ lechenii bolnykh s nespetcificheskoy empiemoy plevry [Dynamic thoracoscopy with the use of thoracoport in the treatment of patients with nonspecific pleural empyema]. Izvestiya vysshikh uchebnykh zavedeniy. Povolzhskiy region - News of Higher Educational Institutions. Volga Region, 4 (16), 99-107 [in Russian].

5. Duzhii, I.D., Hresko I.Ia., \& Mishchenko, Iu.O. (2016). Pytannia epidemiolohii empiiemy plevry [Issues of epidemiology of pleural empyema]. Ukrainskyi pulmonolohichnyi zhurnal Ukrainian Pulmonology Journal, 3, 60-62 [in Ukrainian].

6. Makarov, V.V. (2008). Sovremennye aspekty sanatsii plevralnoy polosti u bolnykh s ostroy empiemoy plevry [Modern aspects of pleural cavity sanation in patients with acute pleural empyema]. Bukovynskyi medychnyi visnik - Bukovyna Medical Journal, 12 (3), 39-41 [in Russian].

7. Shulutko, A.M., Ovchinnikov, A.A., Yasnogorodskiy, O.O., \& Motus, I.Ya. (2006). Endoskopicheskaya torakalnaya khirurgiya: rukovodstvo dlya vrachey [Endoscopic thoracic surgery: a guide for physicians]. Moscow: Meditsina [in Russian].

8. Lee, S.F., Lawrence, D., Booth, H., Morris-Jones, S., Macrae, B., \& Zumla, A. (2010). Thoracic empyema: current opinions in medical and surgical management. Curr. Opin. Pulm. Med., 16 (3), 194-200. doi: 10.1097/MCP.0b013e32833883f5. Available from: https://www.ncbi.nlm.nih.gov/pubmed/?term=Thoracic+e mpyema\%3A+current+opinions+in+medical+and+surgical+man agement+S.+F.+Lee\%2C+D.+Lawrence\%2C+H.+Booth

9. Tseymakh, E.A., Levin, A.B., Zimonin, P.E., Samuylenkov, A.M. (2009). Empiemy plevry. Chastota vozniknoveniya, punktsionnaya terapiya, zakrytoe drenirovanie plevralnoy polosti. Chast I [Empyema of the pleura. Frequency of onset, puncture therapy, closed drainage of the pleural cavity. Part I]. Tuberkulez I bolezni legkikh - Tuberculosis and Lung Diseases, 8, 3-9 [in Russian].

10. Walker, C.A., Shirk, M.B., Tschampel, M.M., \& Visconti, J.A. (2003). Intrapleural alteplase in a patient with complicated pleural effusion. Ann. Pharmacother, 37(3), 376-379. doi: 10.1345/aph.1C248. Available from: http://journals.sagepub. com/doi/10.1345/aph.1C248

11. Porcel, J.M., \& Light, R.W. (2009). Parapneumonic pleural effusions and empyema in adults: current practice. Rev. Clin. Esp., 209 (10), 485-494.

12. Khrupkin, V.I., Gostishchev, V.K., Zolotarev, D.V., \& Degtyareva, E.V. (2014). Torakoskopicheskie metody V kompleksnom lechenii nespetsificheskoy empiemy plevry i gnoyno-destruktivnykh zabolevaniy legkikh [Thoracoscopic methods in the complex treatment of nonspecific pleural empyema and purulent-destructive pulmonary diseases]. Khirurgiya Surgery, 10, 15-20 [in Russian].

13. Matveev, V.Yu., Khasanov, R.M., Gaifullin, R.F., Galkov E.M., Fakhrutdinov R.N., \& Ibragimov, A.I. (2012). Kombinirovannoe khirurgicheskoe lechenie empiemy plevry $\mathrm{s}$ primeneniem videotorakoskopii [Combined surgical treatment of pleural empyema with videothorakoscopy]. Aktualnye problemy meditsiny - Actual Problems of Medicine, 2 (8), 111-116 [in Russian].

14. Yasnogorodskiy, O.O., Shulutko, A.M., Pinchuk, T.P., Gandybina, E.G., Kachikin, A.S., Nasirov, F.N.,...Gryaznov, S.E. (2017). Evoliutsiya metodov kompleksnogo lecheniya bolnykh $\mathrm{s}$ nespetsificheskoy empiemoi plevry [Evolution of complex treatment methods of patients with nonspecific pleural empyema]. Khirurgiya - Surgery, 4, 24-29 [in Russian].

15. Shypulin, P.P., Baidan, V.V., Martyniuk, V.A. (2009). Mozhlyvosti videotorakoskopichnoi rezektsii lehen v torakalnii khirurhii [Possibilities of videotracoscopic lung resection in thoracic surgery]. Klinichna khirurhiia - Clinical Surgery, 9, 43 - 46 [in Ukrainian].

16. Luh, S.P., Chou, M.C., Wang, L.S., Chen, J.Y., Tsai, T.P. (2005). Video-assisted thoracoscopic surgery in the treatment of complicated parapneumonic effusions or empyemas: outcome of 234 patients. Chest, 127, 1427-1432. doi: 10.1378/ chest.127.4.1427. Available from: https://www.ncbi.nlm.nih.gov/ pubmed/15821225

17. Potaris, K., Mihos, P., Gakidis, I., \& Chatziantoniou, C. (2007). Video-thoracoscopic and open surgical management of thoracic empyema. Surg. Infect. (Larchmt), 8 (5), 511-517. doi: 10.1089/sur.2006.049. Available from: http://online.liebertpub. com/doi/abs/10.1089/sur.2006.049

18. Ng, T., Ryder, B.A., Maziak, D.E., \& Shamji, F.M. (2008). Treatment of postpneumonectomy empyema with debridement followed by continuous antibiotic irrigation. J. Am. Coll. Surg., 206, 1178-1183. doi: 10.1016/j.jamcollsurg.2008.01.005. Available from: http://www.journalacs.org/article/S10727515(08)00022-7/fulltext

19. Izmaylov, E.P., Rodin, S.D., \& Naumova, T.A. (2011). Rezultaty primeneniya videoassistirovannoy minitorakotomii pri lechenii ostroy empiemy plevry [Results of video-assisted minithoracotomy use in the treatment of acute pleural empyema]. Abstracts of Papers. 21st National Congress on Diseases of Respiratory Organs. Ufa, October 25-28. (pp.101-102) [in Russian]. 20. Bongiolatti, S., Voltolini, L., Borgianni, S., Borrelli, R., Tancredi, G., Viggiano, D., \& Gonfiotti, A. (2017). Uniportal thoracoscopic decortication for pleural empyema and the role of ultrasonographic preoperative staging. Interact. Cardiovasc. Thorac. Surg., 24 (4), 560-566. doi: 10.1093/icvts/ivw423. Available from: https://academic.oup.com/icvts/article-lookup/ doi/10.1093/icvts/ivw423

21. Kolbashova, Yu.N., \& Yevtikhov, R.M. (2012). Primenenie mini-invazivnykh metodik $\mathrm{v}$ lechenii empiemy plevry, oslozhnennoy bronkhoplevralnym svishchom [The use of mini-invasive techniques in the treatment of pleural empyema complicated by bronchopleural fistula]. Vestnik Ivanovskoy meditsinskoy akademii - Journal of Ivanovo Medical Academy, 17 (2), $75-76$ [in Russian].

22. Sigal, E.I., Zhestkov, K.G., Burmistrov, M.V., \& Pikin, O.V. (2012). Torakoskopicheskaya khirurgiya [Thoracoscopic surgery]. Moscow: Dom knigi [in Russian]. 
23. Shevchenko, A.A., Koshevoy, A.V., Kashkarov, E.A., Motora, V.I., \& Myatlik, A.V. (2015). Etapnoe lechenie postpnevmonektomicheskoy empiemy [Stage treatment of postpneumonectomy empyema]. Dalnevostochnyy meditsinskiy zhurnal - Far Eastern Medical Journal, 4, 108-110 [in Russian]. 24. Tseymakh, E.A., Levin, A.V., Shvetsov, I.V., \& Broder, I.A. (2011). Primenenie klapannoy bronkhoblokatsii i videotorakoskopii $\mathrm{v}$ kompleksnom lechenii piopnevmotoraksa [The use of valvular bronchial blocking and videothoracoscopy in the complex treatment of piopneumothorax]. Endoskopicheskaya khirurgiya - Endoscopic Surgery, 2, 14-17 [in Russian].

25. Slobodenyuk, I.F., Polezhaev, A.A., Nekhay, K.Kh., Shkuratov, A.G., Sudnishchikov, V.V., Emelyanov, I.V., \& Bobyreva, M.G. (2011). Takticheskie voprosy lecheniya empiemy plevry, oslozhnennoy bronkhoplevralnymi svishchami [Tactical issues of pleural empyema treatment complicated by bronchopleural fistulas]. Tikhookeanskiy meditsinskiy zhurnal Pacific Medical Journal, 1, 41-44 [in Russian].

26. Haghshenasskashani, A., Rahnavardi, M., Yan, T.D., \& McCaughan, B.C. (2011). Intrathoracic application of a vacuumassisted closure device in managing pleural space infection after lung resection: is it an option? Interact. Cardio Vasc. Thorac.
Surg., 13, 168-174. doi: 10.1510/icvts.2011.267286. Available from: https://academic.oup.com/icvts/article-lookup/doi/10.1510/ icvts.2011.267286

27. Groetzner, J., Holzer M., Stockhausen D., Tchashin I., Altmayer M., Graba M., \& Bieselt R. (2009). Intrathoracic application of vacuum wound therapy following thoracic surgery. Thorac. Cardiovasc. Surg., 57, 417-420. doi: 10.1055/s-00291185907. Available from: https://www.thieme-connect.de/DOI/ DOI?10.1055/s-0029-1185907

28. Barskiy,B.G.,Zheskov,K.G.,Kozachenko, V.M.,Bykov,A.N., \& Kuznetsova, O.A. (2015). Odnoportovye torakoskopicheskie programmirovannye sanatsii i minitorakostomiya s vakuumterapiyey $\mathrm{v}$ lechenii empiemy plevry [Single-port thoracoscopic programmed sanation and mini-thoracoscopy with vacuum therapy in the treatment of pleural empyema]. Vysokotekh. Med. High-Tech. Med., 3, 30-39 [in Russian].

29. Perentes, J.Y., Abdelnour-Berchtold, E., Blatter, J., Lovis, A., Ris, H.B., Krueger, T., \& Gonzalez M. (2015). Vacuum-assisted closure device for the management of infected postpneumonectomy chest cavities. J. Thorac. Cardiovasc. Surg., 149 (3), 745-750. doi: 10.1016/j.jtcvs.2014.10.052. Available from: http://www. jtcvsonline.org/article/S0022-5223(14)01557-8/fulltext

\section{O.YU. TRONINA}

Odesa National Medical University

\section{MODERN APPROACHES TO THE ACUTE PLEURAL EMPYEMA TREATMENT (LITERATURE REVIEW)}

Acute pleural empyema (APE) remains one of the most complex diseases that not only thoracic surgeons face every year, but also physicians and general practitioners. Despite modern pharmacology success and surgical techniques rapid development, the results of APE treatment usually remain unsatisfactory. This may be associated with improper treatment and late diagnosis of pneumonia complications. The drainage of the pleural cavity was considered to be standard in APE surgical treatment for many years. But in situations when the patient has APE with multiple chambers, each of them had to be drained separately, which creates additional difficulties for both the surgeon and the patient. In recent years, various types of videocorticoscopic surgeries (VCS) have been widely used in the world, including APE treatment. However, discussions on the correct tactics of using VCS in the APE treatment continue. Also, the issues of combating APE complications remain relevant. In their treatment there is no common opinion of specialists. Therefore, the aim of our work was to analyze modern domestic and foreign literature concerning APE treatment using videothoracoscopic minimally invasive technologies.

VCS allow successfully combining the possibilities of closed and open surgical interventions in thoracic surgery. The undoubted VCS advantages are also blood loss reduction and time needed to perform intervention itself. If there is no opportunity to perform a fully closed VCS, it can be supplemented with a mini thoracotomy. Analysis of this technique usage experience indicates much wider possibility of intrapleural manipulations. The implementation of VCS in APE allows to achieve the inpatient treatment term reduction and to reduce the percentage of process chronicity cases. Severe complications of APE, such as residual cavities and pleuro-pulmonary fistulas, require an individual approach to every patient. Vacuum therapy could be a modern and promising method for APE residual cavities treatment.

Key words: videothoracoscopic operations; pleural empyema; pleuro-pulmonary fistula; residual cavity. 


\section{Е. Ю. ТРОНИНА}

Одесский национальный медицинский университет

\section{СОВРЕМЕННЫЕ ПОДХОДЫ К ЛЕЧЕНИЮ ОСТРОЙ ЭМПИЕМЫ П.ЛЕВРЫ (ОБЗОР ЛИТЕРАТУРЫ)}

Острая эмпиема плевры (ОЭП) остается одним из самых сложных заболеваний, с которым ежегодно сталкиваются не только торакальные хирурги, но и терапевты и врачи общей практики. Несмотря на успехи современной фармакологии и стремительное развитие хирургических методик, результаты лечения ОЭП часто остаются неудовлетворительными. Это часто связано и с неправильным лечением и поздней диагностикой осложнений пневмонии. Стандартом хирургического лечения ОЭП много лет считали дренирование плевральной полости. Но в ситуациях, когда у больного имеется многоосумкованная ОЭП приходилось дренировать каждое осумкование отдельно, что создает дополнительные трудности как для хирурга, так и для больного. В последние годы широкое распространение в мире получили различные виды видеоторакоскопических операций (ВТО), в том числе и при лечении ОЭП. Однако продолжают вестись дискуссии о правильной тактике использования ВТО при ОЭП. Также остаются актуальными вопросы борьбы с осложнениями ОЭП, в лечении которых нет единого мнения специалистов. Поэтому целью нашей работы был анализ современной отечественной и зарубежной литературы по тактике лечения больных ОЭП с использованием современных видеоторакоскопических малоинвазивных технологий.

ВТО позволяют успешно сочетать в себе возможности закрытых и открытых оперативных вмешательств в торакальной хирургии. Безусловным преимуществом ВТО также является уменьшение кровопотери и времени, необходимого на выполнение самого вмешательства. При невозможности выполнить полностью закрытую ВТО можно дополнить ее мини-торакотомией. Анализ опыта применения такой методики свидетельствует о значительно более широких возможностях интраплевральных манипуляций. Выполнение ВТО при ОЭП позволяет добиться сокращения срока стационарного лечения и снизить процент случаев хронизации процесса. Тяжелые осложнения ОЭП, например остаточные полости и плевро-легочные свищи, требуют индивидуального подхода к каждому больному. Современным и перспективным методом борьбы с остаточными полостями при ОЭП является вакуум-терапия.

Ключевые слова: видеоторакоскопические операции; эмпиема плевры; плевро-легочные свищи; остаточная полость. 